\title{
Cementum, apical morphology and hypercementosis: A probable adaptive response of the periodontal support tissues and potential orthodontic implications
}

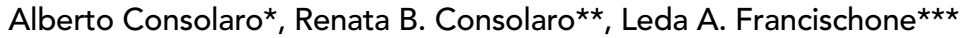

\begin{abstract}
Information about orthodontic movement of teeth with hypercementosis is scarce. As cementum deposition continues to occur, cementum is expected to change the shape of the root and apex over time, but this has not yet been demonstrated. Nor has it ever been established whether it increases or decreases the prevalence of root resorption during orthodontic treatment. The unique biological function of the interconnected network of cementocytes may play a role in orthodontic movement and its associated root resorptions, but no research has ever been conducted on the topic. Unlike cementum thickness and hypercementosis, root and apex shape has not yet been related to patient age. A study of the precise difference between increased cementum thickness and hypercementosis is warranted. Hypercementosis refers to excessive cementum formation above and beyond the extent necessary to fulfill its normal functions, resulting in abnormal thickening with macroscopic changes in the tooth root, which may require the delivery of forces that are different from conventional mechanics in their intensity, direction and distribution. What are the unique features and specificities involved in moving teeth that present with hypercementosis? Bodily movements would be expected to occur, since inclination might prove difficult to achieve, but would the root resorption index be higher or lower?
\end{abstract}

Keywords: Cementum. Hypercementosis. Tooth movement. Root resorption.

How to cite this article: Consolaro A, Consolaro RB, Francischone LA. Cementum, apical morphology and hypercementosis: A probable adaptive response of the periodontal support tissues and potential orthodontic implications. Dental Press J Orthod. 2012 Jan-Feb;17(1):21-30.
" The authors report no commercial, proprietary, or financial interest in the products or companies described in this article.

* Head Professor, Bauru School of Dentistry/University of São Paulo (USP). Professor, Graduate Studies of Ribeirão Preto Dental School (FORP/USP).

** Substitute Professor and PhD in Pathology, Araraquara Dental School (FOA-UNESP). Professor, Faculdades Adamantinenses Integradas.

*** Professor and PhD, Sacred Heart University (USC-Bauru). 
Hypercementosis refers to an adaptive change in the periodontal ligament characterized by increased cementum thickness on the root surface above and beyond the extent necessary to fulfill its normal functions, resulting in abnormal thickening with macroscopic changes in shape (Figs 1, 2 and 3). Its incidence has not yet been determined, but its prevalence ranges between 1.05 and 5.67\% in Brazilian patients. ${ }^{6,21}$

Hypercementosis induces acceleration in the deposition of new layers of cementum by cementoblasts (Fig 4). These cells overlay the root surface in between the periodontal fibers, also known as Sharpey's fibers, which attach to or fuse with the cementum collagen. At the interface with the root surface the cementoblasts yield a slow but steady deposition of the cementum organic matrix into lamellar layers, alternately mineralizing the latter, and thereby determining gross basophilic incremental lines in the tissue sections stained with hematoxylin and eosin (Figs 3 and 4). Cementum thickening occurs by a rhythmic process: After deposition, each new layer of cementum is mineralized by the previous layer. The last layer, a non-mineralized layer, can also be called precementum. When deposition takes place prior to tooth eruption the cementum can be classified as primary. After eruption, the cementum can be defined as secondary and is formed in response to functional demands. ${ }^{22,27,28,29}$

The cementoblasts interact with the root surface and the other surfaces of the cell body relate to the extracellular matrix of the periodontal ligament, of which collagen fibers are part. Cementoblast membrane proteins are externally connected with components of the extracellular matrix such as fibronectin, for example. Transmembrane proteins known as integrins are internally connected to cytoskeleton proteins, imparting a stable form and mobility to the cells.

The cementum overlays the root surface, thereby "hiding" or isolating the periodontal ligament dentin and, at the same time, allowing the attachment of periodontal collagen fibers for support and tooth articulation (of the gomphosis type) with the periodontal ligament along the alveolar wall. ${ }^{10,30}$ The term cementum stems from the Latin caementum or "cement": Stone particles used to make mortar.

Periodontal activities such as absorbing, directing and distributing forces applied to the tooth may move the periodontal fibers and other components

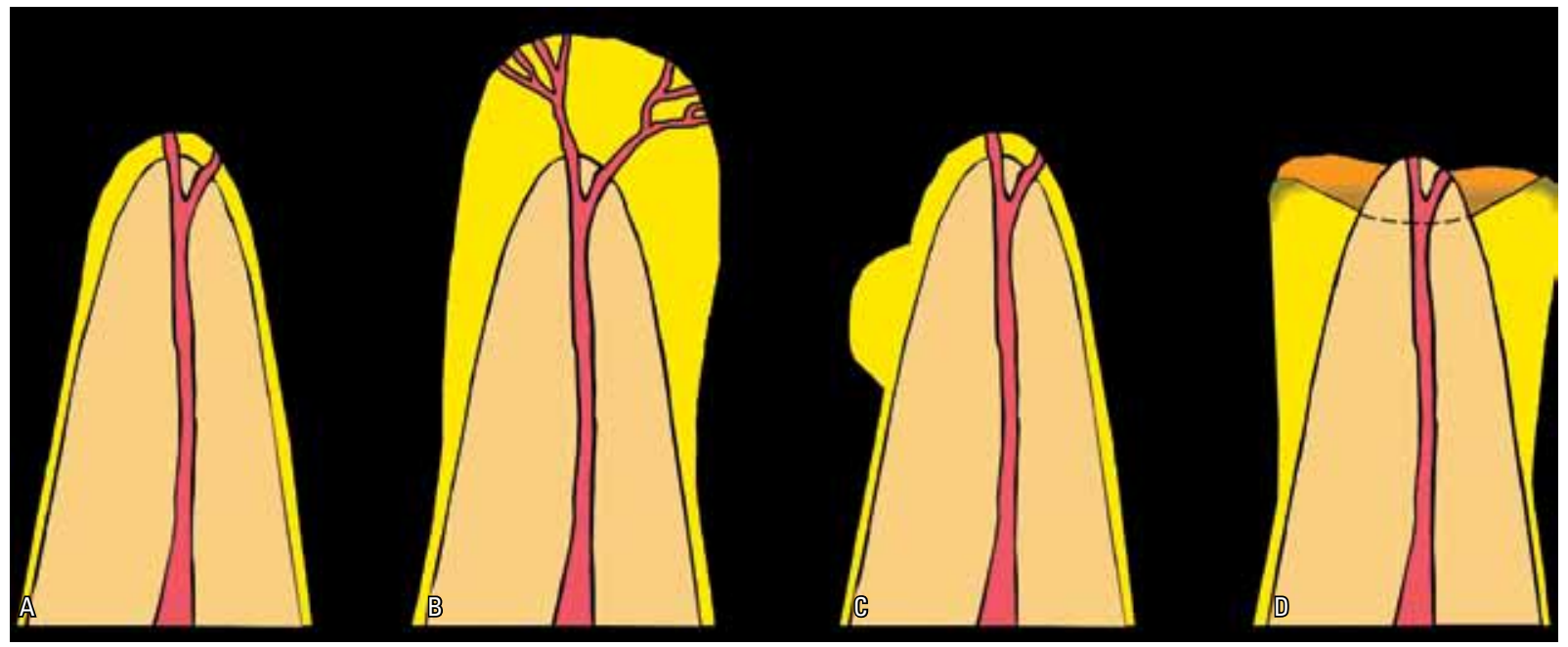

FIGURE 1 - Morphological types of hypercementosis: In (A) the root is normal; in (B) diffuse hypercementosis, when the root assumes a club shape. In (C) focal or localized hypercementosis, which is restricted to an isolated root surface; in (D) hypercementosis in the shape of a shirt sleeve cuff, which does not involve the most apical part and occurs on the periphery, as result of chronic periapical lesion (Source: Pinheiro ${ }^{25}$ ). 

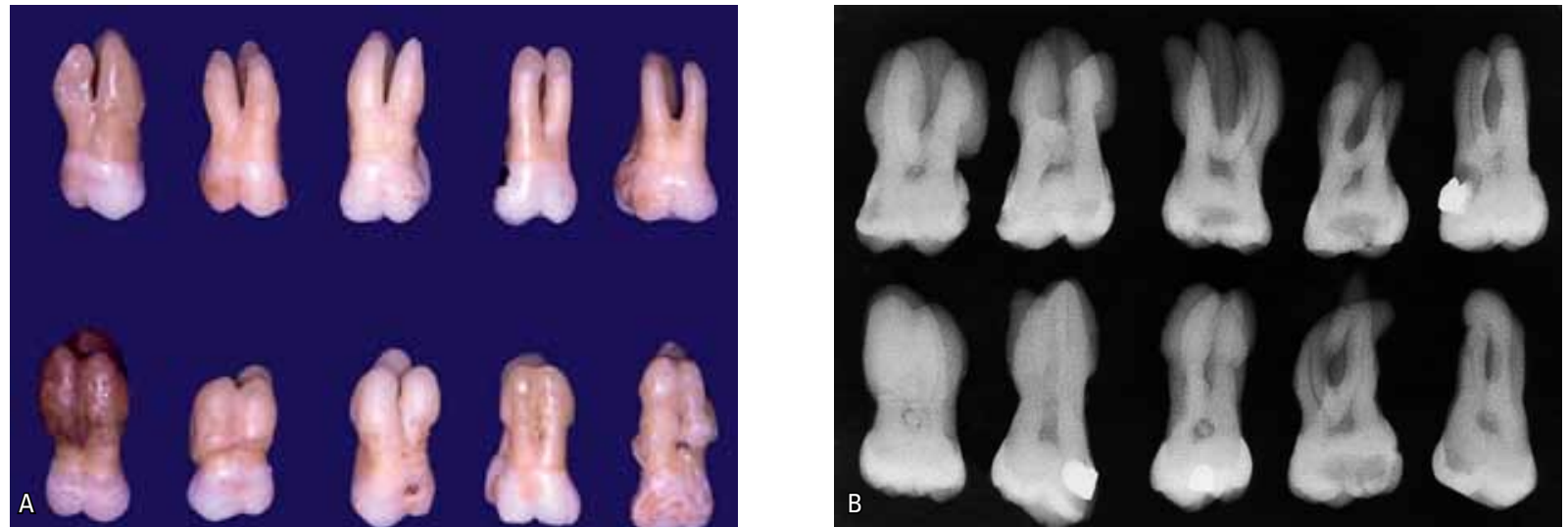

FIGURE 2 - Upper molars are the most affected teeth with hypercementosis, in various intensity levels, as these specimen, obtained from a sample of 21,573 teeth. ${ }^{6}$

of the extracellular matrix, as well as deform the cementoblasts via the cytoskeleton by means of integrins. Cytoskeleton deformation may produce the necessary stimulus for the cellular stress, resulting in increased release of mediators and cementum matrix synthesis on the root surface.

In other words, hypercementosis can be an adaptive response to an increased periodontal functional demand. This may result from an acceleration in deposition or an increase in the amount of cementum matrix as a way to attach more often and in a wider area the periodontal fibers whose function is under greater demand. The collagen in the cementum forms a fibrillar network, which is sometimes parallel to the surface, sometimes irregularly distributed, ${ }^{28,29}$ and when associated with Sharpey's fiber attachments, produces a veritable system of transmission and dissemination of forces applied to the tooth.

Tooth cementum has some intriguing features when compared with bone tissue: It does not undergo remodeling but experiences lifelong deposition. ${ }^{1,2,9,15,31}$ Cementoblasts are formed throughout a person's life from progenitor cells located in the periodontal ligament (Fig 4). Two non-collagenic proteins may be related to the chemical attraction, adhesion and differentiation of precementoblasts on the root surface: Bone sialoprotein (BSP) and osteopontin (OPN). ${ }^{5,26}$

\section{CEMENTUM CELLULARITY AND APICAL MORPHOLOGY}

Cementum matrix deposition by cementoblasts in the cervical and middle thirds of the root does not include cells and the cementum is usually ultimately classified as acellular. Amid the layers of cementum deposition no gaps can be found with cementocytes inside them (Figs 4, 5 and 6).

In the cementum located at the end of the middle third and throughout the apical third the gaps are occupied by cementocytes with numerous interconnecting extensions in the form of a "spider web." The cementocytes are also found in large numbers in furcation areas. Their gaps interconnect with the cementocytes, making metabolic exchanges with the odontoblastic extensions of the neighboring dentin (Figs 4, 5 and 6).

In the bone, a network of osteocytes is formed through contact with approximately twenty cells. This interconnecting network exchanges fluids and mediators, keeping the mineralized bone matrix metabolically active and connected to the internal and external bone surfaces. It is likely that this interconnecting network may capture structural deformations by applying compressive forces and bone stretching, which results in cytoskeleton deformation and release of mediators that stimulate adaptive cellular activities on the surfaces of medullary and cortical spaces. 

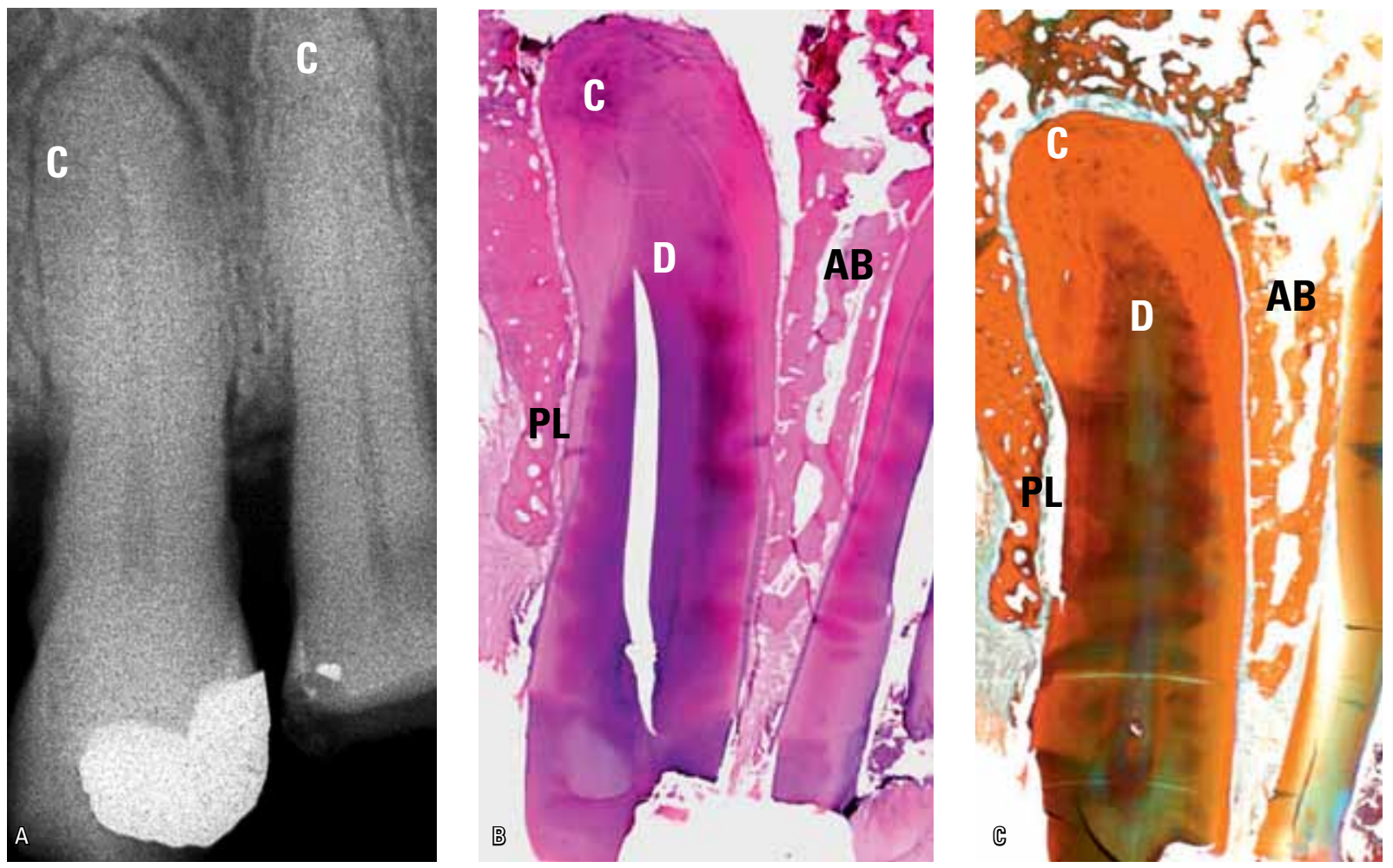

FIGURE 3 - Radiographic and microscopic aspects of hypercementosis. The new cementum layers (C) are continuously deposited on the root surface, changing the apical morphology, which tends to become rhomboid. The limits between the dentin (D) and the cementum remain preserved on tissue sections. The periodontal ligament $(\mathrm{PL})$ continues present with normal structure and organization, joining the tooth to the alveolar bone $(\mathrm{AB})(\mathrm{B}=\mathrm{HE}$, $2.5 x ; \mathbf{C}=$ polychromic, $2.5 \mathrm{x})$.

In the cementum, it is likely that the interconnecting network of cementocytes may help to control the root apex shape. Cementum is not as hard as dentin. ${ }^{16}$ Stretching and compression forces delivered to the root, especially to the thinner and more delicate apical third, can deform the interconnecting network of cementocytes and their cytoskeleton. On the surface, the layer of cementoblasts can receive stimuli from cementocytes to slow down or accelerate cementum deposition and respond appropriately to the perceived stimulus.

In conceptual and hypothetical terms one may infer that hypercementosis is an adaptive response of periodontal tissues geared toward increasing the area of support and distribution of occlusal forces. This manner of increasing its surface ratio relative to the neighboring bone can play an important role in coping with excessive occlusal loads ${ }^{6}$ and even in the absence of antagonists, when occlusal forces are hardly present at all. ${ }^{6}$ Hypercementosis can function as a way to increase the retention or dental attachment in the alveolar bone.

By addressing these issues it may be possible to explain why there are two types of cementum in terms of cellularity: Acellular and cellular, the latter present almost exclusively in the apical thirds and furcation regions, which are under a great deal of mechanical pressure in periodontal physiology. Cementum is the deposition of organic matrix after mineralization while adaptive responses are directly related to the depositing cells, i.e., cementoblasts (Fig 4). As a dental tissue, cementum consists of an almost passive attachment structure for periodontal fibers. The active, responsive portion of the tissue is represented by cementoblasts and cementocytes. The term acellular when referring 

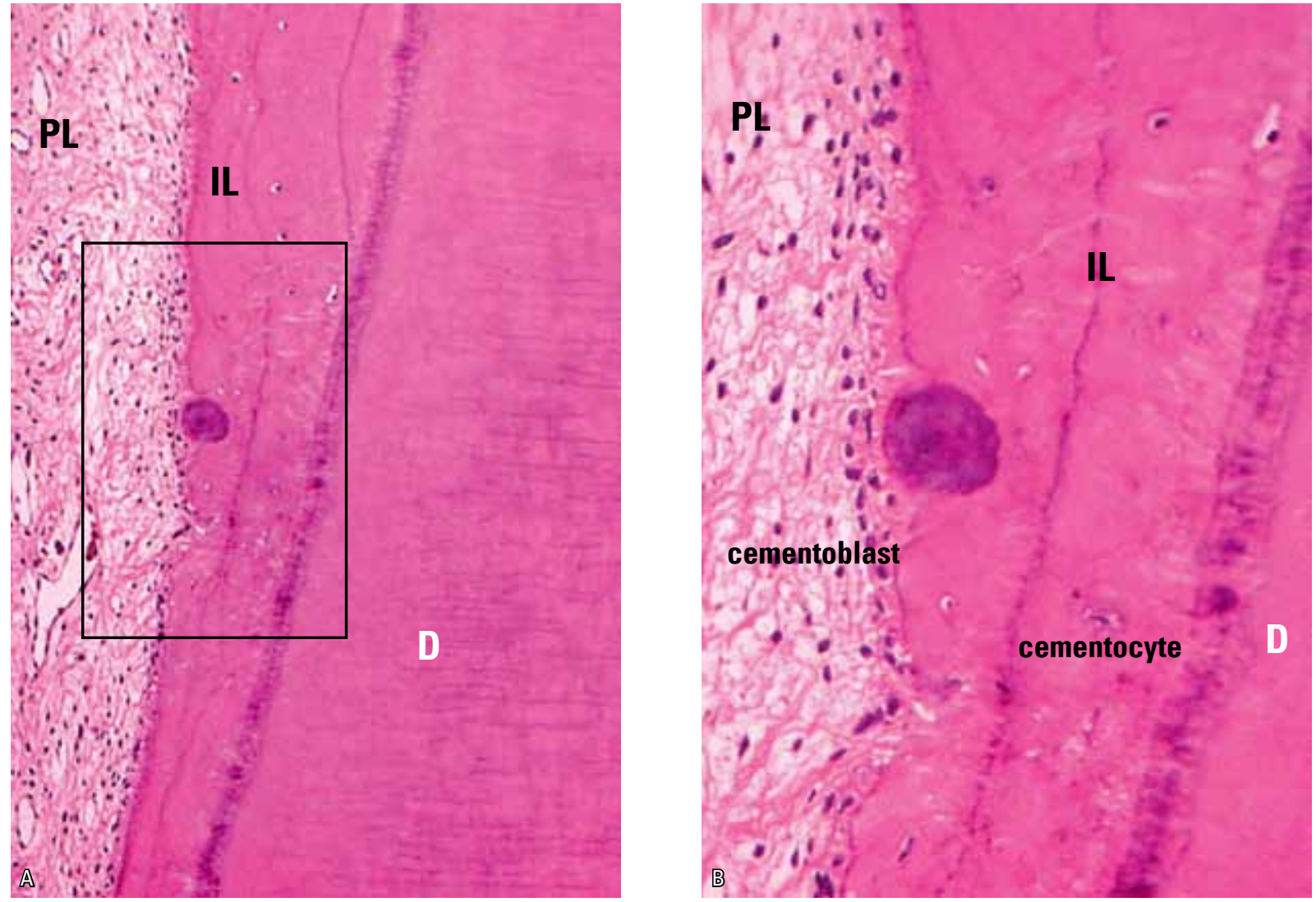

FIGURE 4 - Microscopic aspects of hypercementosis, in tissue sections obtained by demineralization and stained with HE. The periodontal ligament (PL), cementoblasts and cementocytes inside their lacunae can be seen. In the cementum, with thickness increasing from bottom to top, basophilic increment lines can be observed (IL) from the dentin (D). The more basophilic spherical area, corresponds to the cementicle included by the continuous and accelerated cementum deposition (HE, $\mathbf{A}=10 \mathrm{x}$ and $\mathbf{B}=25 \mathrm{x})$.

to the cementum is not perfectly suitable because, despite the absence of cementocytes, cementum contains numerous cementoblasts on its surface.

\section{FIBRILLAR CEMENTUM AND AFIBRILLAR OR INTERMEDIATE CEMENTUM}

The organic portion of cementum is predominantly constituted of type I collagen, a fibrous component of various tissues, amid proteoglycans and water. In turn, its mineral part comprises 45 to $50 \%$ of its volume and is made up predominantly of calcium and phosphate in the form of hydroxyapatite.

The root structure comprises a tissue known as cementum, which actually is not deposited by cementoblasts and nor does it contain fibrillar components in its structure. Intermediate cementum is comprised of a thin layer of 10 to $20 \mu \mathrm{m}$ deposited over the outer portion of the dentin during root formation and synthesized by Hertwig's epithelial root sheath (HERS). ${ }^{11,22,24}$

Prior to fragmenting, HERS deposits intermediate cementum, isolating the dentin from the follicular and periodontal components of the tooth germ. ${ }^{8}$ As it derives from the more cervical part of the enamel organ, HERS synthesizes this thin layer of proteins, which are similar to those of the ename $1^{17,18,19}$ without a fibrillar component. It was therefore named intermediate cementum as it is located between the dentin and the future fibrillar cementum to be deposited by the cementoblasts derived from the dental follicle or sac. 

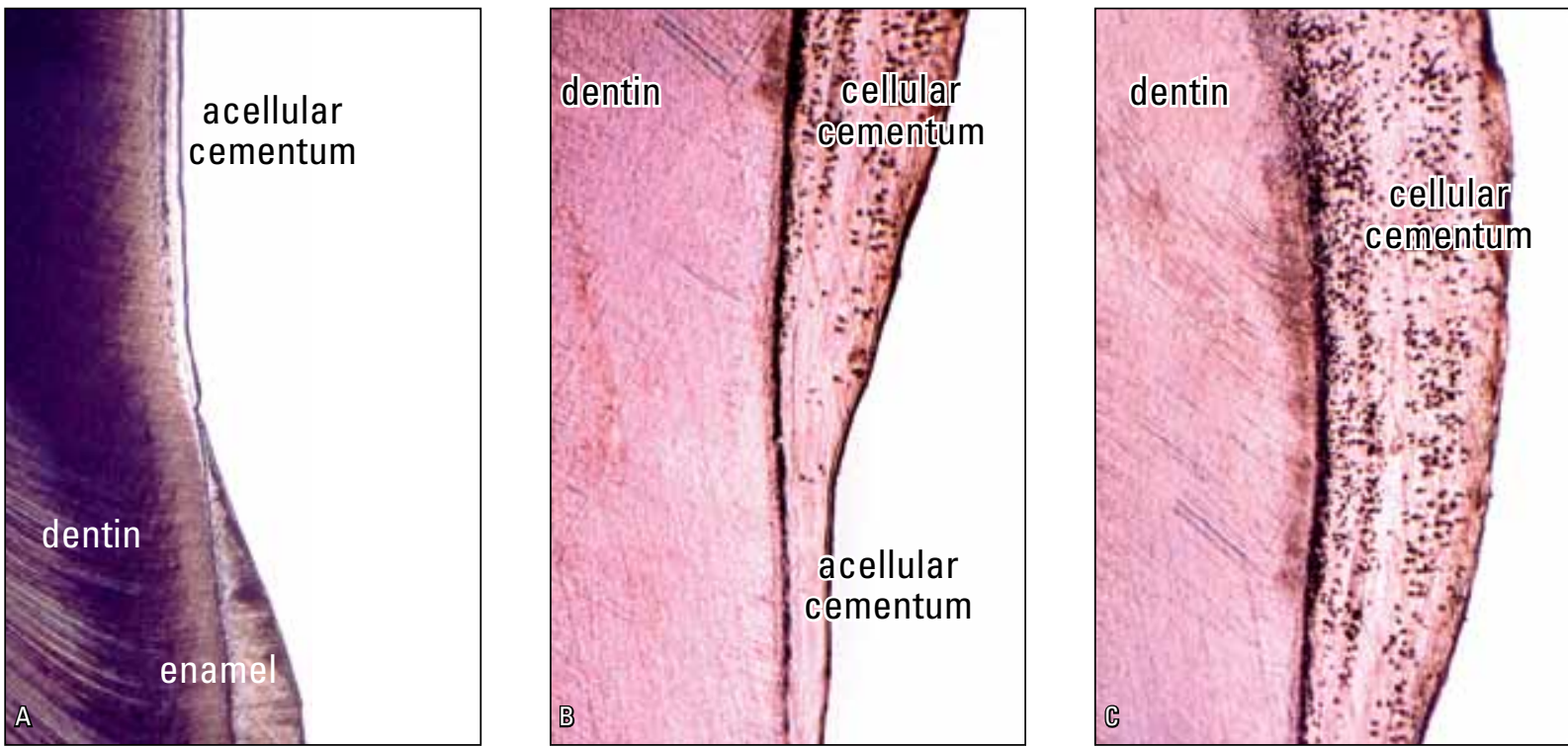

FIGURE 5 - Hypercementosis in tissue sections obtained by grinding, with no demineralization or staining. The cementum presents a uniform thickness in the cervical and middle thirds. The lacunae are in great quantity in the cellular cement in the apical third. Note the growing thickness of the tooth cementum from bottom (cervical) to top (apical) $(\mathbf{A}=4 \mathrm{x}, \mathrm{B}=10 \mathrm{x}$ and $\mathbf{C}=25 \mathrm{X})$.

It is only after the deposition of this thin layer of intermediate cementum that HERS fragmentation occurs, creating space on the root surface and thereby allowing the dental follicle cells to differentiate into cementoblasts and initiate cementum deposition. It is probable that the molecular components of intermediate cementum and its interaction with the dental follicle cells play an important part in the differentiation of these cells into cementoblasts, and at the beginning of cementum deposition.

Apparently, the intermediate cementum-an afibrillar and acellular tissue-has no direct relationship with the root cementum, but from a structural and anatomical point of view one can say that between the dentin and cementum there is a thin afibrillar, adamantine and aprismatic layer. The presence of enamel on the tooth roots can be observed in the teeth of some animals, such as in the incisors of mice. Although originally described in 1920 by Hopewell-Smith ${ }^{12}$ as a homogeneous, hyaline layer, intermediate cementum was only given its definitive name in 1927 by Bencze. ${ }^{4}$
INCREASED THICKNESS OF CEMENTUM AND HYPERCEMENTOSIS: MORPHOLOGICAL ASPECTS AND POTENTIAL ORTHODONTIC IMPLICATIONS

Hypercementosis can be defined as an excessive formation of cementum above and beyond the extent necessary to fulfill its normal functions, resulting in abnormal thickening and changes in the macroscopic shape of the root. ${ }^{25}$ Once in place, hypercementosis modifies root morphology, both internally and externally, especially in the apical third. In three previous papers the authors of this study investigated the morphological aspects of hypercementosis. ${ }^{3,6,25}$

Based on the analysis of 21,573 teeth it was found ${ }^{6}$ that the teeth most compromised by hypercementosis were the upper molars (5\%), followed by the upper premolars $(0.88 \%)$ and lower premolars $(0.86 \%)$, and the lower molars $(0.74 \%)$. The canines showed very little impairment, the upper incisors were seldom affected and there were no hypercementosis cases among lower incisors. 
Among the factors closely associated with hypercementosis is functional stress, as is the case in patients with bruxism, teeth clenching and occlusal trauma. However, many cases of hypercementosis can be found in teeth without antagonists or teeth with destroyed crowns, but with no sign of previous existence of such process. Indeed, there is no evidence of the adaptive and or reactional nature of increased cementum thickness and hypercementosis.

Chronic periapical lesions such as periapical granulomas are another cause often associated with hypercementosis (Fig 1). In the peripheral part of granulomas, the root cementum increases its thickness as a response to inflammatory stimuli arising out of the widespread tissue and cellular mediators. Once the chronic periapical lesion of extracted teeth is removed along with this type of hypercementosis, the apex surrounded laterally by increased cementum produces a shape resembling a "shirt sleeve cuff."

Hurzeler and Zander ${ }^{15}$ measured the cementum thickness of single-rooted teeth from 110 randomly selected human teeth, which were serially cut from the apex to the cementoenamel junction (CEJ). The teeth of subjects aged 17 years on average showed a $0.076 \mathrm{~mm}$ cementum thickness while those with an average age of 59 years had three times that thickness, averaging $0.206 \mathrm{~mm}$.

In another work, Zander and Hurzeler ${ }^{31}$ analyzed the thickness of the cementum of 233 single-rooted teeth of subjects between 11 and 76 years old. There was a gradual increase in apical cementum commensurate with aging. In 20-yearold patients the apical cementum showed on average a $0.095 \mathrm{~mm}$ thickness; in 30-year-olds, an average of $0.125 \mathrm{~mm}$; in 40 -year-olds, $0.155 \mathrm{~mm}$; in 50-year-olds, $0.185 \mathrm{~mm}$ and an average thickness of $0.215 \mathrm{~mm}$ in 60 -year-old patients.

With the purpose of comparing the cementum in different ethnic groups, Muller and Zander ${ }^{23}$ studied 61 single-rooted teeth from Indians and found a slightly smaller cementum thickness in the various age groups than in North Americans from the state of Minnesota.

Information about orthodontic movement of teeth with hypercementosis is scarce in the literature. As cementum deposition occurs steadily, it should therefore change the root and apex shape throughout one's lifetime, but this has not yet been demonstrated. These morphological changes could potentially increase or decrease the prevalence of root resorption in orthodontic treatment since it is a known fact that the root and apex are predictive factors of root resorption when they show a triangular shape or are shaped like a pipette, or lacerated. ${ }^{7}$

Could an increase in cementum thickness be in any way related to a different prevalence of tooth resorption during orthodontic treatment in adults as a result of changes in the root and apex shape? Or might it be due to specific biological factors inherent in the cementum and its interconnecting network of cementocytes?

Root and apex shape has not yet been correlated with patient age. For example, is a triangular shape of the tooth root and apex more prevalent in youths, adults or the elderly? Shouldn't the rhomboid or quadrangular shape of the dental apex be more prevalent in the elderly? Azaz et $\mathrm{al}^{1,2}$ reported- in two samples of 60 and 72 unerupted canines-an increase in cementum thickness and in the prevalence of hypercementosis with aging.

In light of these issues and peculiarities of the cementum, both conceptually and in practice, one should carefully distinguish between increases in cementum thickness due to aging and/or functional demand, and a diagnosis of hypercementosis. A more bulging or rounded root and root apex (Figs 1, 2 and 3) may be due to increased cementum thickness which would reflect a variability in root morphology, but within normal limits.

Hypercementosis refers to excessive cementum formation above and beyond the extent necessary to fulfill its normal functions, resulting in 

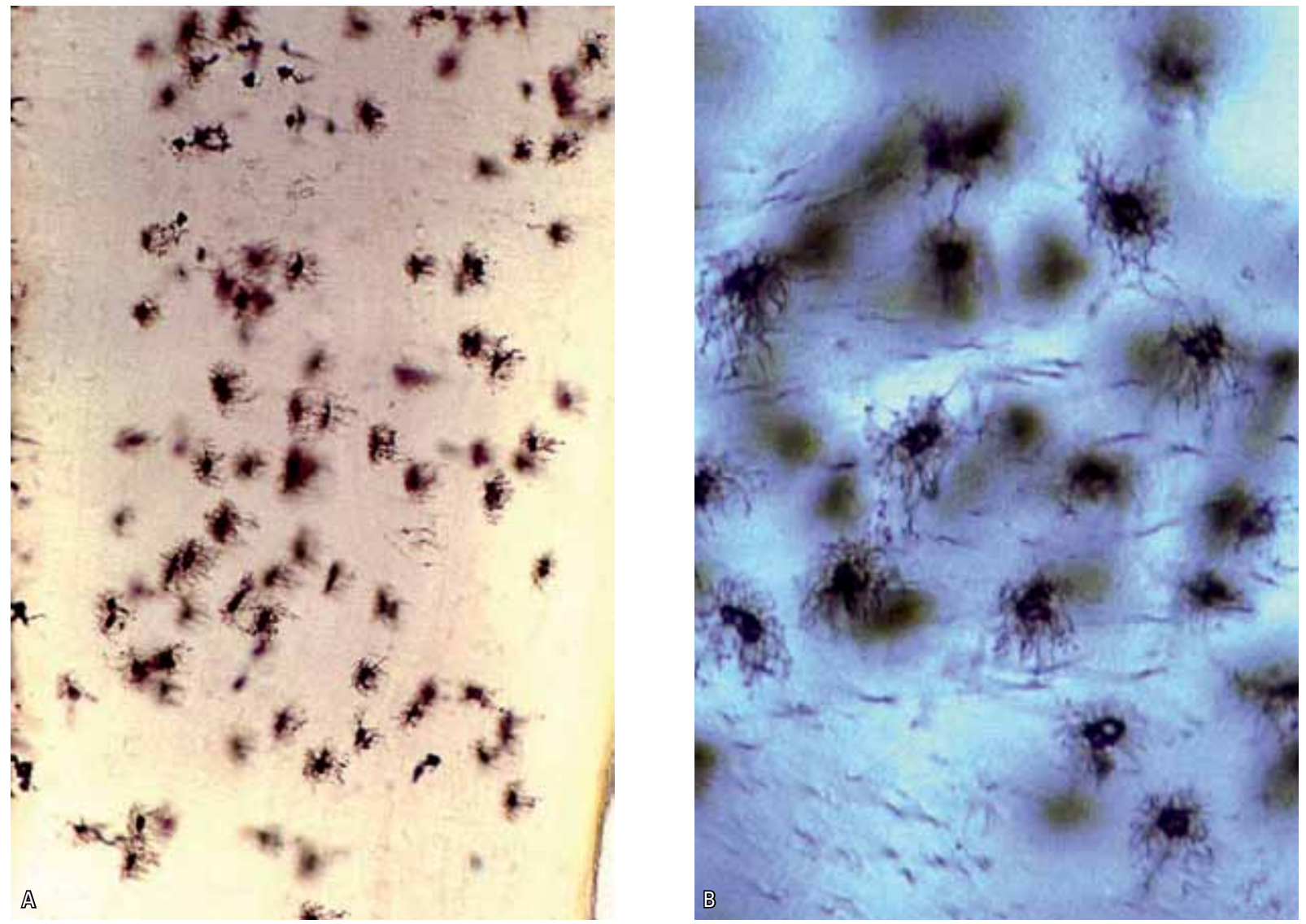

FIGURE 6 - Cementocytes lacunae in area with hypercementosis in tissue sections obtained by grinding, with no demineralization, or staining. Numerous canaliculi can be seen where a number of cytoplasmatic extensions were irregularly distributed and communicated with other cementocytes, allowing for a communicating network of signals and stimuli $(\mathbf{A}=40 \mathrm{x}$ and $\mathbf{B}=100 \mathrm{x})$.

abnormal thickening with macroscopic changes in the tooth root, which may require the delivery of forces that are different from conventional mechanics in their intensity, direction and distribution. What are the unique features and specificities involved in moving teeth with hypercementosis? Teeth with hypercementosis should be amenable to induced tooth movement, although one published case report $\mathrm{t}^{20}$ disclosed difficulties in the effective displacement of compromised teeth.

In their investigations, Humerfelt and Reitan ${ }^{13,14}$ sought to analyze the mobility of teeth with hypercementosis during the orthodontic treatment of three patients of the same family but the issue was associated with deciduous teeth and permanent infraocclusion and/or late eruption.
In other words, their research did not focus only on cases involving teeth with hypercementosis. Their conclusions correlated hypercementosis with tooth loss or eruption delay as well as tooth impaction, and even with dentoalveolar ankylosis resulting from orthodontically moving these teeth, although their inferences were not grounded in reliable data.

An analysis of the effects of continuous cementum deposition on the shape of the root and apex is warranted. These morphological changes may influence the predictive factors of root resorption during orthodontic treatment. In like manner, the effects of orthodontic movement in teeth with hypercementosis have not yet been examined. It may be much more difficult to apply forces and 
achieve satisfactory clinical outcomes, as found in a single case published by Mattar Neto et al. ${ }^{20}$ The movements should probably be almost always bodily movements since it would be challenging to obtain them in the presence of hypercementosis. Would these teeth with hypercementosis, which were moved, exhibit a greater or lesser root resorption index?

In 1999 Barros $^{3}$ analyzed in tissue sections the internal and external anatomy of dozens of teeth with hypercementosis, from a macroscopic point of view using a stereomicroscope with and without clearing the teeth with xylol as well as optical microscopy. He noted that hypercementosis increased the number of lateral and accessory canals, as well as apical deltas, in addition to narrowing the main channel in the apical third, which also resulted in changes in the direction of the foramen. From an organizational and structural standpoint, the cementum in teeth with hypercementosis appeared normal under optical microscopy.

Moreover, in 2005, Pinheiro ${ }^{25}$ examined macroscopically 576 permanent teeth with hypercementosis using stereomicroscopy, radiography and scanning electron microscopy. In $85.24 \%$ of the teeth examined the roots took on the shape of a club; $8.16 \%$ of the teeth exhibited a localized form and $6.6 \%$ of the teeth displayed a "shirt sleeve cuff" shape.

Contemporary orthodontics requires further detailed studies on the impact of age-related increased cementum thickness on the biology of induced tooth movement and associated root resorptions. It also requires further analysis of the physical and biological characteristics of hypercementosis in the context of orthopedic and orthodontic treatment.

\section{FINAL CONSIDERATIONS}

There is no definitive evidence to address issues such as:

1. If cementum deposition occurs on a continuous basis, is it expected to change the root and apex shape throughout the person's entire life. However, these changes have not yet been studied. Would these morphological changes act by increasing or by decreasing the prevalence of root resorption in orthodontic treatment?

2. Is the triangular shape of the tooth root and apex more prevalent in youths, adults or the elderly? Shouldn't the rhomboid or quadrangular shape of the dental apex be more prevalent in the elderly?

3. Would an increased thickness of cementum with aging have a positive or negative correlation with the prevalence of tooth resorptions in the orthodontic treatment of adults?

4. Should an accurate diagnosis be established based on the relationship between (a) what appears to be an increased cementum thickness inducing an anatomical change in the normal shape of the root and (b) a hypercementosis, that might involve changes in the shape of the human tooth root.

5. What are the unique features and specificities involved in moving teeth that present with hypercementosis?

6. What is the function of cementocytes? What is the role of cementocytes in induced tooth movement? And in apical tooth resorptions during orthodontic treatment?

7. Could intermediate cementum be present throughout the whole extent of the root surface? Does it determine a higher or lower prevalence of tooth resorptions during orthodontic movement? Does it influence periodontal reorganization after induced tooth movement?

Hopefully, these issues will encourage further research on the unique effects of orthodontic movement on teeth with increased thickness and/or hypercementosis. 


\section{REFERENCES}

1. Azaz B, Ulmansky M, Moshev R, Sela J. Correlation between age and thickness of cementum in impacted teeth. Oral Surg Oral Med Oral Pathol. 1974;38(5):691-4.

2. Azaz B, Michaeli Y, Nitzan D. Aging of tissues of the roots of nonfunctional human teeth. Oral Surg Oral Med Oral Pathol. 1977;43(4):572-8.

3. Barros LAP. Estudos macro e microscópico da morfologia do terço dentário apical na hipercementose [tese]. Bauru (SP): Universidade de São Paulo; 1999.

4. Blackwood HJJ. Intermediate cementum. Br Dent J. 1957; 102(9):345-50.

5. Bosshardt DD, Selvig KA. Dental cementum: the dynamics tissue covering of the root. Periodontol 2000. 1997;13:41-75.

6. Consolaro A, Oliveira LU, Vasconcelos MHF. Determinação da prevalência da hipercementose e suas implicações etiopatogênicas. Odontol mod. 1987;14(3):6-14.

7. Consolaro A. Reabsorções dentárias nas especialidades clínicas. $2^{a}$ ed. Maringá: Dental Press; 2005.

8. El Mostehy MR, Stallard RE. Intermediate cementum. J Periodontol. 1968; 3(1):24-9.

9. Gootlieb B. Continuous deposition of cementum. J Am Dent Assoc. 1943;30(11):842-7.

10. Hammarstrom $L$, Alatli I, Fong CD. Origins of cementum. Oral Dis. 1966; 2(1):63-9.

11. Harrison JW, Roda RS. Intermediate cementum: development, structure, composition and potential functions. Oral Surg Oral Med Oral Pathol Oral Radiol Endod. 1995;79(5):624-33.

12. Hopewell-Smith A. Concerning human cementum. J Edent Res. 1920; 2(1):59-76

13. Humerfelt A, Reitan K. Effects of hypercementosis on the movability of teeth during orthodontic treatment. Angle Orthod. 1966; 36(3):179-89.

14. Humerfelt A, Reitan K. Hypercementosis, its developmental stage and effects on the movability of teeth during orthodontic treatment. Rep Congr Eur Orthod Soc. 1965;41:277-94.

15. Hurzeler B, Zander A. Determination of cementum thickness. J Dent Res. 1958; 37(6):44.

16. Kerr DA. The cementum: its role in periodontal health and disease. J Periodontol. 1931;32:183-9.

17. Lindskog S. Formation of intermediate cement I: early mineralization of aprismatic enamel and intermediate cementum in monkey. J Craniofac Genet Dev Biol. 1982;2(2):147-60.
18. Lindskog S. Formation of intermediate cement II: A scanning electron microscopy study of the epithelial root sheath of Hertwig in monkey. J Craniofac Genet Dev Biol. 1982;2(2):161-9.

19. Lindskog S, Hammarström L. Formation of intermediate cement III: $\mathrm{H}$-tryptophan and $\mathrm{H}$-proline uptake into the epithelial root sheath of Hertwig in vitro. J Craniofac Genet Dev Biol. 1982;2(2):171-7.

20. Mattar Neto A, Vedovello Filho M, Vedovello S, Chiarini P, Young AAA. Tratamento ortodôntico em paciente portador de hipercementose. RGO. 2005;53(2):85-164.

21. Matos ASRC. Levantamento das condições dentárias dos pacientes atendidos nas clínicas da Faculdade de Odontologia de Bauru-USP, através de exames clínico e radiográfico [tese]. Bauru (SP): Universidade de São Paulo; 1985.

22. Mjör IA, Fejerskov O. O periodonto. In: Mjör I A, Fejerskov $\mathrm{O}$, editor. Embriologia e histologia oral humana. São Paulo: Panamericana; 1990. p. 131-76.

23. Muller G, Zander A. Cementum thickness of teeth from India. J Dent Res. 1959;38(4):668.

24. Orban, B. Oral histology and embryology. $3^{\text {rd }}$ ed. St. Louis: Mosby; 1953.

25. Pinheiro BC. Hipercementose: estudo macroscópico, estereomicroscópico, radiográfico e à microscopia eletrônica de varredura. [dissertação]. Bauru (SP): Universidade de São Paulo; 2005

26. Saygin NE, Giannobile WV, Somerman M. Molecular and cell biology of cementum. Periodontol. 2000;24:73-98.

27. Schroeder HE, Page RC. The normal periodontium: In: Schluger S, Youdelis RA, Page RC, editors. Periodontal disease: basic phenomena, clinical management and occlusal and restorative interrelationships. $2^{\text {nd }}$ ed. Philadelphia: Lea \& Febiger; 1990. p. 3-52

28. Selvig KA. An ultrastructural study of cementum formation. Acta Odontol Scand. 1964;22:105-20.

29. Selvig KA. The fine structure of human cementum. Acta Odontol Scand. 1965;23:423-41.

30. Ten Cate AR. Oral histology: development, structure and function. $5^{\text {th }}$ ed. St. Louis: Mosby; 1998.

31. Zander A, Hurzeler B. Continuous cementum apposition. J Dent Res. 1958;37(6):1035-44.
Submitted: December 12, 2011

Revised and accepted: December 15, 2011

\section{Contact address}

Alberto Consolaro

E-mail: consolaro@uol.com.br 